\title{
ARBITRAGEM E O DESENVOLVIMENTO COMO LIBERDADE
}

\author{
Adriana Silva Maillart* \\ Ricardo Soares Stersi dos Santos**
}

\begin{abstract}
Resumo
O presente artigo tem por finalidade analisar se a arbitragem pode ser considerada um instrumento para a promoção do desenvolvimento como liberdade no Brasil. Conclui-se que, ao estar fundamentada no princípio da autonomia das partes, a arbitragem se conecta a ideia de liberdade apresentada por Amartya Sen, na teoria de desenvolvimento, podendo ser considerado um meio de desenvolvimento. Utilizou-se para a construção desta pesquisa, o método hipotético-dedutivo de abordagem e as técnicas bibliográfica e documental de pesquisa.
\end{abstract}

Palavras-chaves: arbitragem; desenvolvimento; liberdade; autonomia privada; ADRs.

\section{ARBITRATION AND DEVELOPMENT AS FREEDOM}

\begin{abstract}
This article aims to analyze whether arbitration can be considered an instrument for promoting development as freedom in Brazil. It concludes that, as the arbitration is based on the principle of autonomy of the parties, it's connected to the idea of freedom of Amartya Sen's theory of development and can be considered a way of development. For the elaboration of this research, the hypothetical-deductive method of approach and the bibliographic and documentary research techniques were used.
\end{abstract}

Keywords: arbitration; development; freedom; private autonomy; ADRs.

\section{Introdução}

A promulgação da Lei n. 9307, de 23 de setembro de $1996^{1}$ (Lei de arbitragem), com sua posterior ampliação em 2015 por meio da Lei n. 13129, de 26 de maio $^{2}$, pode ser considerada um avanço ao tratamento dispensado ao instituto no Brasil ao possibilitar uma expansão na utilização da arbitragem no Brasil, principalmente em matéria comercial. Isso porque, com a Lei de Arbitragem, abandonou-se grande parte das incertezas existentes anteriormente em razão de legislação inadequada para regular a matéria. Com a solução de problemas anteriores referentes à falta de autonomia e de eficácia da cláusula compromissória

\footnotetext{
* Pós-Doutora pela Universidade Federal de Santa Catarina (UFSC). Mestre e Doutora em Direito pela Universidade Federal de Santa Catarina (UFSC). Professora de Cursos de pós graduação Lato e Strictu Sensu. Sócia e consultora da empresa AXM Consultoria e Treinamento. E-mail: adrissilva@ gmail.com.

** Mestre e Doutor em Direito pela Universidade Federal de Santa Catarina (UFSC). Professor dos Cursos de Graduação e de Pós-Graduação em Direito da UFSC (Mestrado e Doutorado acadêmico e Mestrado profissional). E-mail: rstersi@ hotmail.com.

BRASIL. Lei 9307 de 23 de setembro de 1996. Disponível em: http://www.planalto.gov.br/ccivil_03/leis/19307.htm. Acesso em 11 set. 2021.

${ }^{2}$ BRASIL. Lei 13129 de 24 de maio de 2015. Disponível em http://www.planalto.gov.br/ccivil_03/_Ato20152018/2015/Lei/L13129.htm\#art1. Acesso em 11 set. 2021.
} 
e à necessidade de homologação da sentença arbitral pelo Poder Judiciário, o aumento de casos levados à arbitragem foi notório.

O Centro de Arbitragem e Mediação da Câmara de Comércio Brasil-Canadá (CAMCCBC), por exemplo, criado em 1979, a instituição mais antiga a utilizar a arbitragem no Brasil, tinha julgado somente três casos até o ano de 1998. (MAGRO, 2002). No final de 2019, a CAM-CCBC já havia administrado na sua história mil e setenta e nove procedimentos arbitrais, sendo que somente no ano de 2019 ingressaram noventa e sete novos procedimentos e foram finalizadas cento e uma arbitragens. O tempo médio dos procedimentos arbitrais entre 2017 e 2019 foi de pouco mais de treze meses em média e a principal matéria submetida à arbitragem em 2019 se relacionava a contratos de cunho societário, contratos de fornecimento de bens e/ou serviços e os contratos de construção. Dos quatrocentos e treze procedimentos arbitrais ainda em andamento na CAM/CCBC em 2019, quarenta e um envolviam a administração pública. Os valores envolvidos nos casos levados a CAM-CCBC, desde 2015, atingiu o montante de $\mathrm{R} \$ 61,9$ bilhões. $^{3}$

$\mathrm{Na}$ pesquisa de Lemes (2020), que procura fazer uma coleta de dados em oito Câmaras de arbitragem no Brasil (incluindo a CAM/CCBC), no ano de 2018 foram iniciadas duzentas e noventa e duas novas arbitragens e em 2019 foram duzentas e oitenta e nove. Em 2019 havia novecentos e sessenta e sete procedimentos arbitrais em andamento (entre novos e antigos). Em 2018 os montantes discutidos nos procedimentos arbitrais em andamento somavam um total de quase $\mathrm{R} \$ 81,5$ bilhões.

Assim não há dúvida de que nos últimos anos se pôde sentir um crescimento significativo da utilização da arbitragem no país. Entretanto, indaga-se aqui se a arbitragem, como está instituída no Brasil, pode proporcionar avanços em termos de desenvolvimento.

Do ponto de vista do desenvolvimento econômico, as pesquisas sobre economia e justiça realizadas por Pinheiro comprovam que a existência de um "bom judiciário" ocasiona o crescimento econômico, por garantir os direitos de propriedade e o cumprimento dos contratos. Entretanto, elas também demonstram que o sistema judiciário brasileiro não tem conseguido abranger as características de um Judiciário eficiente: "agilidade, previsibilidade, imparcialidade e custo de acesso" (PINHEIRO, 2004).

Para compensar as falhas do Judiciário e favorecer o crescimento da economia, Posner, (2004) indica a arbitragem como uma das alternativas para alavancar o crescimento econômico, do ponto de vista da economia e justiça. De tal forma que, Pinheiro (2001, p. 11) assevera que, "mesmo em economias com bons sistemas judiciais, essas instituições operam de forma complementar ou como uma alternativa de baixo custo ao judiciário".

Entretanto, o ponto de vista econômico é apenas uma das faces da análise do desenvolvimento. Sendo assim, este estudo, tendo como referencial teórico os ideais de Amartya Sen (2000), tem como objetivo analisar o desenvolvimento sobre um cunho mais humano, avaliando a arbitragem sobre o aspecto do desenvolvimento como liberdade.

A liberdade defendida por Sen (2000) é considerada um produto social, em que as disposições sociais visam a expandir as liberdades individuais e, ao mesmo tempo, essas liberdades individuais são usadas não só para melhorar a vida de cada um, mas também para tornar as disposições sociais mais apropriadas e eficazes.

Liberdade, no viés de desenvolvimento, constitui-se, portanto, na possibilidade de eliminação das privações que limitam as escolhas e as oportunidades das pessoas de exercer ponderadamente sua condição de agente.

${ }^{3}$ CÂMARA DE COMÉRCIO BRASIL-CANADÁ. Relatório anual 2019: fatos e números. Disponível em: https://ccbc.org.br/cam-ccbc-centro-arbitragem-mediacao/arbitragem-estatisticas/. Acesso em 11 set. 2021. 
Assim, utilizando-se do método hipotético-dedutivo de abordagem e as técnicas bibliográfica e documental de pesquisa, pretende-se analisar se a arbitragem pode ser considerada um instrumento de desenvolvimento como liberdade no Brasil.

\section{A ideia de desenvolvimento de Amartya Sen}

O grande mérito da ideia de desenvolvimento, em Amartya Sen (2000) está em retomar a luta pela liberdade com valores igualitários, resgatando o ideal de liberdade de outrora, tão distorcido pelos ideários do liberalismo econômico. Percebe a liberdade individual como um produto social e concilia, assim, os conceitos de capacidade individual (autonomia) e capacidade social (igualdade), nessa concepção de desenvolvimento.

Esses conceitos (liberdade individual/autonomia e igualdade) tempos atrás eram considerados conflitantes entre si, pois, como específica Bobbio (1996, p. 42), "para o liberal, a finalidade principal é a expansão da personalidade individual, abstratamente considerada como um valor em si; para o igualitário, essa finalidade é o desenvolvimento harmonioso da sociedade".

Como um meio-termo, Rawls (2002) e Sen (2000) observam a liberdade e a igualdade como valores que não conflitam entre si, de tal forma que, para Sen (2001, p. 54), '[...] a liberdade está entre os possíveis campos de aplicação da igualdade, e a igualdade está entre os possíveis padrões de distribuição da liberdade" e "[...] a liberdade é uma das mais influentes ideias sociais, e sua relevância para a análise da igualdade e da justiça é forte e de grande alcance" (SEN, 2001, p. 118).

Afirma que essa condição faz parte da eficácia do processo de desenvolvimento, pois a liberdade dada ao agente "melhora o potencial das pessoas para cuidar de si mesmas e para influenciar o mundo, questões centrais para o processo de desenvolvimento (SEN, p. 2000, p. 33)". E acrescenta ainda que muitos "indivíduos são privados não só de bem-estar, mas do potencial para levar uma vida responsável, pois esta depende do gozo de certas liberdades básicas. Responsabilidade requer liberdade" (SEN, 2000, p. 322).

Amartya Sen (2000, p. 297) afirma ainda que:

[...] o uso do raciocínio socialmente responsável e de ideias de justiça relaciona-se estreitamente à centralidade da liberdade individual [...] a alternativa ao apoio exclusivo na responsabilidade individual não é, como às vezes se supõe, o chamado "Estado babá".

Para Sen (2000, p. 323), “a visão arbitrariamente restrita de responsabilidade individual [...] tem de ser ampliada, reconhecendo-se não meramente o papel do Estado, mas também as funções de outras instituições e agentes", ditames que compõem também sua abordagem de justiça.

Dessa forma, o sistema jurídico pode contribuir de maneira significativa para a expansão e a garantia dos indivíduos ao considerá-los agentes ativos de mudanças. Vale ressaltar que sistema jurídico, aqui, quer dizer não apenas o acesso ao Poder Judiciário, mas a existência de leis que incentivam o desenvolvimento humano e o acesso a outros meios de solução de controvérsias, como a arbitragem, que será tratada a seguir.

\section{As bases principiológicas da arbitragem}


De acordo com (Carmona 2009, p. 31), a arbitragem é uma forma alternativa de administração de controvérsias “[...] através da intervenção de uma ou mais pessoas que recebem seus poderes de uma convenção privada, decidindo com base nela [...] sendo a decisão destinada a assumir a mesma eficácia da sentença judicial [...]"

Cahali (2013, p. 85) destaca a arbitragem como uma forma heterocompositiva, assim como o processo judicial e destaca que:

As partes capazes, de comum acordo, diante de um litígio, ou por meio de uma cláusula contratual, estabelecem que um terceiro [...] terá poderes para solucionar a controvérsias [...] sendo que a decisão terá a mesma eficácia de uma sentença judicial.

Nos conceitos de arbitragem acima apresentados são claros pelo menos dois aspectos relevantes: a) a existência da arbitragem depende de um consenso prévio das partes; b) a decisão proferida pelo árbitro tem a mesma eficácia da sentença proferida pelo juiz.

Como pontua Silva (2005, p. 141-143), a ampla liberdade de contratação que autoriza o acordo das partes a respeito de diversos pontos da arbitragem deriva do princípio da autonomia privada. Assim, analisando os fundamentos da arbitragem, pode-se identificar que a autonomia privada é um dos seus princípios basilares. Por meio desse princípio, as partes poderão, por exemplo, nomear e escolher o número de árbitros, que no Brasil deverá ser sempre em número ímpar; escolher as normas aplicáveis ao procedimento arbitral e a matéria de fundo (mérito) da arbitragem.

Não há dúvidas de que a liberdade que as partes possuem na arbitragem, quando comparada com aquela atinente ao processo judicial, é muito maior (SANTOS, 2004, p. 40). Assim, o principal mérito da lei de arbitragem foi atribuir às partes a capacidade de solucionar seus próprios conflitos, como expõe Pucci (2001, p. 11-12):

O fato de que, atualmente, no Brasil os cidadãos possam escolher entre a via judicial e a via arbitral para resolver seus conflitos, mostra um amadurecimento da condição do cidadão frente ao Estado. $\mathrm{O}$ indivíduo, que é livre e que procura proteger seus direitos e interesses, é quem surge como mais capacitado para definir se, na sua situação particular, é melhor submeter a decisão de uma controvérsia perante o juiz ou perante o árbitro. A vigência da nova lei sobre arbitragem mostra um amadurecimento da sociedade brasileira que, respeitando a livre iniciativa dos particulares, oferece a estes dois caminhos alternativos, duas opções, para resolver as controvérsias relativas a direitos patrimoniais disponíveis.

Há uma tendência mundial para que as partes solucionem seus próprios litígios, e a lei de arbitragem colabora para tanto. Na arbitragem, as partes têm uma participação maior e mais efetiva na administração dos conflitos sendo consideradas, portanto, agentes do processo. Por meio das ações que poderão adotar ao longo do procedimento arbitral, as partes procuram orientar o juízo arbitral e resolver os litígios da forma mais amigável possível já que precisam entrar em acordo para escolher o direito aplicável, o prazo de duração do processo arbitral, quem e como será escolhido o árbitro ou a instituição que administrará a arbitragem, entre outros "consensos" previstos na lei de arbitragem dentre de limites como a ordem pública.

Como explica Racine (1999, p. 8-26), a ordem pública exprime um princípio simples: o interesse social se impõe ao interesse particular. Entretanto, este ponto de vista não 
é considerado por Rocha (1998, p. 20) que percebem na arbitragem "a aplicação do mecanismo do mercado à solução dos conflitos de interesses".

Na concepção de Rocha (1998, p. 13), o ressurgimento da arbitragem se dá por dois motivos: pela deficiência do aparelho judiciário e "pela hegemonia da ideologia liberal, que estimula o recurso ao sistema de mercado como mecanismo de regulação das ações sociais, inclusive dos conflitos".

Como bem observa Barral (2000, p. 62-63), parece mais adequado admitir que o ressurgimento da arbitragem se deve muito mais à redefinição do âmbito privado do que à hegemonia do liberalismo tradicional, pois "equivaler arbitragem à decorrência do liberalismo econômico é negligenciar a tendência da sociedade em se auto-regular, em detrimento do Estado".

Essa redefinição do âmbito privado deve-se muito às grandes demandas de solução de controvérsias chegadas ao conhecimento do Judiciário, após o alargamento dos direitos alcançados principalmente no final da década de 1970 e na década de 1980 . Esse excesso de demanda ao Poder Judiciário, denominado também de crise do Poder Judiciário, já ocorria em 1974, quando um estudo foi empreendido pelo Supremo Tribunal Federal por provocação do Ministro Eloy da Rocha. Como explica Roberto Rosas (2000, p. 103):

Dizia o magistrado da impossibilidade da vida judiciária pelo excesso de processos, e de outras causas, acarretando a crise do Judiciário. Pediu, então, o Presidente da República um estudo da crise e a formulação das soluções. Então, o Supremo Tribunal encorajou-se no recolhimento de sugestões, que formaram cerca de noventa volumes, constituindo o mais sério levantamento do problema, e enviado ao Executivo. Nada foi feito, até que, o Presidente Geisel editou a Emenda Constitucional $\mathrm{n}^{\mathrm{o}}$ 7, de 13.4.1977, também apelidado de "Pacote de Abril", porque viera no meio da crise institucional, que impôs o recesso do Congresso.

Os movimentos sociais de acesso à Justiça no Brasil começaram a se intensificar com a transformação legislativa a partir da década de 1980. Essas transformações expandiram a gama de direitos protegidos ${ }^{4}$ mas também promoveram a expansão e os incentivos as formas

\footnotetext{
${ }^{4}$ Foram criadas, por exemplo, a Lei de Procedimento de Arrolamento de Bens por Partilha Amigável (Lei ${ }^{\circ}$ 7.019), de 1982; a Lei de Política Nacional do Meio Ambiente (Lei n ${ }^{\circ}$ 6.938/81); Lei de Proteção dos Direitos Difusos e Coletivos (Lei $\mathrm{n}^{\circ}$ 7.347/85); Lei de Proteção da Tutela Jurisdicional de Interesses das Pessoas Portadoras de Deficiência e da Ação Civil Pública de Responsabilidade por Danos causados aos Investidores no Mercado de Valores Imobiliários (Leis n 7.853 e n ${ }^{\circ} 7.913$, de 1989), Estatuto da Criança e do Adolescente (Lei $\mathrm{n}^{\circ}$ 8.069/90) e o Código de Defesa do Consumidor (Lei n ${ }^{\circ}$ 8.078/90). No entanto, o apogeu da ampliação desses direitos se deu com a Constituição Federal da República Federativa do Brasil de 1988 (CF/88), denominada por Ulisses Guimarães de "Constituição Cidadã", que teve influência significativa dos movimentos sociais, e "consagrando e alargando o âmbito dos direitos fundamentais, individuais e sociais, prevendo a criação de mecanismos adequados para garanti-los, especialmente no que se refere ao acesso à justiça [...]", como ressalta Paulo Cezar Pinheiro Carneiro (1999, p. 48). Como assevera este autor (CARNEIRO, 1999, p. 49-51), entre as matérias tratadas pela Constituição Federal de 1988, tratou-se de consagrar a igualdade material, garantindo, ao menos no papel, a redução das desigualdades sociais. Garantiu-se também a assistência judiciária gratuita aos necessitados e viabilizou-se a criação de juizados especiais para assuntos de menor complexidade nas áreas civil e criminal, nos casos de crimes de menor potencial ofensivo. Essa constituição viabilizou, ainda, a criação da justiça de paz; estendeu a ação civil pública a todos os direitos coletivos e difusos, e não só àqueles previstos na Lei $\mathrm{n}^{\circ}$ 7.347/85; criou novos meios de defesa do interesse coletivo, tais como os mandados de segurança coletivo e de injunção; concedeu legitimidade aos sindicatos e entidades associativas para defenderem os direitos coletivos e individuais homogêneos de seus filiados; reestruturou e fortaleceu o Ministério Público, e reorganizou a Defensoria Pública.
} 
alternativas de administração de conflitos que pudessem promover o desafogo do Judiciário. Nesse contexto surgiu a Lei de arbitragem e mais recentemente a Lei n. 13140, de 26 de junho de 2015 (Lei de mediação). ${ }^{5}$

A crise do modelo de administração da justiça no Brasil por meio da preponderância da judicialização já é de muito conhecida pois, em 1996, o Banco Mundial apresentou estudos com dados estatísticos refletindo não só à crise judiciária brasileira, mas também de outros países da América Latina. No ano de 1990, apenas dois anos após a promulgação da Carta Constitucional de 1988, 74\% da população brasileira já reconhecia a administração da justiça no Brasil como regular ou insatisfatória. (DAKOLIAS, 1996, p. 17-19).

Os dados recentes do Relatório Justiça em números de 2020, referentes ao ano de 2019, demonstram o gigantismo do Poder Judiciário no Brasil e das dificuldades decorrentes do modelo de administração da justiça por meio da judicialização dos conflitos: a) os gastos com a justiça no Brasil passaram de 51,2 bilhões de reais em 2009 para 100,2 bilhões de reais em 2019. O custo do Poder Judiciário no Brasil correspondeu a 1,5\% do Produto Interno Bruto (PIB); b) O custo do Poder Judiciário por habitante no Brasil foi de R \$ 315,52 em 2009 para $\mathrm{R} \$ 479,16$ em 2019; c) Em 2019, tramitavam 77,1 milhões de processos judiciais, sendo que em 2009 eram 59,1 milhões. No ano de 2019 ingressaram 30,2 milhões de novos processos e foram baixados 35,4 milhões; d) O número de juízes passou de 15.946 em 2009 para 18.091 (incluindo-se os tribunais superiores) em 2019. Em 2019, o Poder Judiciário possuía 268.175 servidores. (CONSELHO NACIONAL DE JUSTIÇA, 2020)

Como resultado do crescimento de demandas, tem-se que o Poder Judiciário brasileiro não mais conseguiu atender ao crescimento da demanda, originando uma crise, desencadeada pelo aumento da concessão de direitos, que prossegue até hoje ${ }^{6}$. Essa situação veio a causar a insegurança no convívio social, consequência direta dessa demora na prestação jurisdicional, que cria um estado de paralisação e indignação, propiciando um distúrbio social e um estado de incerteza, que causa injustiça não só aos contendores, mas a toda a sociedade.

Não se pode negar que a arbitragem possui no princípio da autonomia privada a sua base e que esse princípio, por sua vez, conecta-se nos ideais de liberdade. Conforme Noronha (1994, p. 111) a autonomia privada "[...] consiste na liberdade de as pessoas regularem através de contratos, ou mesmo de negócios jurídicos unilaterais, quando possível, os seus interesses $[\ldots] . "$

Segundo Strenger (1968, p. 51):

[...] a autonomia da vontade como princípio deve ser sustentada não só como um elemento da liberdade em geral, ma como suporte também da liberdade

\footnotetext{
${ }^{5}$ BRASIL. Lei 13140, de 26 de junho de 2015. Disponível em: http://www.planalto.gov.br/ccivil_03/_ato20152018/2015/lei/113140.htm. Acesso em 12 set. 2021.

${ }^{6}$ Neste sentido, Lima (1999, p. 16) afirma que, “com efeito, às técnicas mercantis, práticas e objetivas, bem se ajustam a simplicidade e o informalismo da solução amigável, sem desnecessários tropeços, mais indicada a, por vezes existente, complexidade, urgência e vulto dos negócios, não raro exigindo, no seu trato, conhecimentos especializados. Esta especialização é que, também não raramente, assegura a solução mais pronta, adequada e justa dos próprios conflitos de interesses, do que muito poucos se apercebem. Presteza, adequação e justiça que o Judiciário - tanto mais obstaculado pelo número excessivo de demandas! - não tem e não pode ter. Os magistrados oficiais - com raras e honrosas exceções de praxe - formados, deformados e conformados na contenciosidade, são infensos, via de regra, a meios amigáveis de pacificação dos conflitos. Não dominam - e não têm possibilidade de dominar - as variadas tecnologias (muito menos as "de ponta" que o empresário corre a viabilizar). Reunindo o árbitro, como é comum, a condição de expert, na matéria conflituosa, e de julgador, tem, incomensuravelmente, muitíssimo e maior conhecimento de causa para bem decidir”.
} 
jurídica que é esse poder insuprimível no homem de criar por um ato de vontade uma situação jurídica, desde que este ato tenha objeto lícito.

Para Castro (1999, p. 43) inexiste autonomia da vontade. Trata-se de liberdade autorizada e delimitada pela lei. A liberdade se exerce em espaços determinados pela lei, onde o elemento volitivo do indivíduo se movimenta criando, modificando e extinguindo relações jurídicas.

Contudo, a autonomia presente na arbitragem não está vinculada às ideologias do liberalismo econômico, controlado pelas regras de mercado. Isso porque, a autonomia privada, princípio basilar da arbitragem, não se confunde com a iniciativa econômica ou com a autonomia contratual em sentido estrito. Ela abrange as liberdades pessoais garantidas constitucionalmente, manifestas por meio da própria identidade do indivíduo dentro da órbita dos valores hierarquicamente dispostos na Constituição.

Por autonomia, também se deve entender "a vontade socializada e legalizada [...] representada pelo indivíduo para exercer sua vontade jurídica pelo bem comum" (STRENGER, 2000, p. 72). A manifestação de capacidade individual não deve ser condenada, se não representar um afastamento da comunidade e se incentivar a promoção da capacidade social.

A percepção de que o ser humano é parte de um corpo social e os direitos, inclusive os privados, devem ser exercidos sob a óptica de uma função social. Nesse momento, dá-se importância não só a intenção das partes, mas também aos limites sociais à autonomia das partes, que atribui um perfil mais igualitário aos contratos, já que põe em primeiro lugar o interesse social da ordem pública e de outros limites equivalentes a ela, como por exemplo, a solidariedade social, a boa-fé, a utilidade social, a paridade de tratamento, a segurança, a dignidade humana e a função social.

Vale ressaltar que a autonomia privada não deixa de ser uma expressão de liberdade. Contudo, esta liberdade não é simplesmente analisada do ponto de vista individual, mas também sob o prisma da sociedade, que constituem o ideário igualitário da teoria de desenvolvimento como liberdade de Amartya Sen.

\section{A arbitragem como instrumento do desenvolvimento como liberdade}

Como mencionado anteriormente, há uma tendência mundial para que as partes solucionem seus próprios litígios e a referida tendência se coaduna com a ideia de desenvolvimento de Sen (2000), que visa a estimular a capacidade dos indivíduos por meio da sua condição de agente. Tal ideia pode ser transportada para a arbitragem já que, por meio dessa forma de administração de conflitos a sociedade busca, por ela mesma, canais próprios para solucionar problemas, tornando-se agente e não mera beneficiária do processo ${ }^{7}$. E ainda, a arbitragem prevê limites à autonomia das partes, visando a preservar o interesse social nos acordos de vontades o que a aproxima da importância da ideia de coletividade quando se pensa em desenvolvimento nos termos pretendidos por Sen.

\footnotetext{
${ }^{7} \mathrm{Na}$ teoria de desenvolvimento de Amartya Sen (2000, p. 26), "os indivíduos podem efetivamente moldar seu próprio destino e ajudar uns aos outros. Não precisam ser vistos, sobretudo, como beneficiários passivos de engenhosos programas de desenvolvimento".
} 
Outrossim, é possível enfatizar que a arbitragem colabora para que uma parcela da sociedade, que não é salvaguardada pelo Judiciário, especialmente devido à morosidade e à falta de conhecimento técnico, receba o efetivo acesso à Justiça ${ }^{8}$.

Como a falta de tutela jurisdicional adequada para os litígios também pode ser considerada uma privação de liberdade, segundo Sen (2000), a arbitragem, ao prestar a tutela jurisdicional devida a litígios de caráter patrimonial disponível, pode ser considerada um meio viável de solucionar esse tipo de privação.

Talvez a pior privação de liberdade, na avaliação de justiça e desenvolvimento, seja a não-possibilidade de recorrer ao Poder Judiciário. Entretanto, não permitir que as pessoas solucionem seus litígios por meios mais adequados e mais amigáveis de controvérsias também pode se constituir uma privação de liberdade, por impedir o exercício da capacidade e da condição de agente dos indivíduos.

Esses meios alternativos não devem, por sua vez, ser impostos às partes, como é o caso da arbitragem obrigatória. Isso porque a arbitragem obrigatória fere o princípio da autonomia privada e o princípio da garantia processual (previsto no art. $5^{\circ}, \mathrm{XXXV}$, da CF), que prevê que nenhuma lesão ou ameaça ao direito será (forçosamente) afastada do conhecimento do Poder Judiciário 9 .

Por meio da expressão de vontade presente na arbitragem, o indivíduo demonstra, assim, que recuperou as suas potencialidades de expressão, de movimento, de possibilidade de escolha, inclusive o da opção pela solidariedade (JEANTET, 1986, p. 22). Esse ponto de vista é mais bem explicado por Teixeira (1997), que expõe que

A realidade social pujante em que vivemos não se contenta mais com o modelo individualista das soluções judiciais de antanho. Desde o final do século passado, vem-se construindo um novo perfil, alicerçado na prevalência do interesse social sobre o individual. Daí exigir-se um Judiciário mais participativo e ativista, na busca de uma sociedade mais justa, humana, solidária, contando para isso com instrumentos processuais mais eficientes, a exemplo da ação civil pública, das ações coletivas, dos

\footnotetext{
${ }^{8}$ Luiz Olavo Baptista(apud FIUZA, 1995, p. 38-39)expõe que, "uma demanda ajuizada em São Paulo, em matéria de propriedade industrial ou pretensos direitos de propriedade industrial relativos a um computador, resultou na comprovação prática de duas das queixas: uma delas é o fato de que a demanda se arrastou até que o computador tornou-se obsoleto e autor e réu perdessem o interesse pela demanda; a outra é de que sequer o perito judicial indicado pelo juiz tinha conhecimentos técnicos adequados para poder opinar sobre a questão. A crítica não se limita porém ao juiz e ao perito por ele indicado, mas estende-se aos advogados. Com efeito o advogado do autor organizou suas questões para a perícia técnica de maneira que mostrava a qualquer pessoa, apenas iniciada em informática, que ele sequer havia visto um computador na sua vida. Então, o fato de que juízes e advogados são usualmente generalistas leva à necessidade da criação, em alguns casos, de foros apropriados. Esse fato é reconhecido pelo legislador, que criou o Tribunal Marítimo, os Tribunais do trabalho, que criou na órbita administrativa determinados tribunais especializados, que mantém a Justiça Militar, enfim, que procura separar no foro cível, através de diferentes varas, as conseqüências especializadas, tal como ocorre em São Paulo, em que há varas de acidentes do trabalho, há varas cíveis e criminais, há varas de família, de registros públicos e daí por diante". A criação do Centro de Arbitragem e Mediação por parte da Organização Mundial de Propriedade Intelectual (World IntellectualPropertyOrganization) é outro exemplo dessa adaptação. Como ressalta Hiram Chodosh (1999, p. 9), "the World Intellectual Property Organization opened its Arbitration and Mediation Center nearly five years ago in response to the inability of national court systems to handle the technical and multi-jurisdictional complexity of such disputes".

9 Neste sentido é o posicionamento de Edoardo Flavio Ricci (2004, p. 59-60), para quem "a interpretação majoritária da norma atribui às palavras 'a lei não excluirá' o sentido: 'a lei não excluirá de maneira imperativa'. A expressão 'de maneira imperativa' é o que é preciso acrescentar, para efetivar o princípio de liberdade no qual a arbitragem voluntária encontra seu fundamento".
} 
juizados especiais, do mandado de segurança coletivo, das ações de controle de constitucionalidade. Mecanismos hábeis e eficazes que suplementem a atividade estatal, priorizando o social. Se assim é, não há porque excluir desses mecanismos a arbitragem, em atenção aos interesses de importantes segmentos sociais, aos quais a Justiça oficial não tem dado abrigo satisfatório.

Dos ensinamentos apontados acima, pode-se retirar que a arbitragem não pode ser considerada oriunda da hegemonia da ideologia liberal econômica pois vem auxiliar o Judiciário a transformar a sociedade em algo mais justo, humano e solidário.

Apesar de ser um meio heterocompositivo, a arbitragem pode ser considerada menos litigiosa do que o processo judicial e também um meio de cooperação com o Judiciário.

No momento atual, a arbitragem é considerada um meio hábil, racional e eficiente de solução de disputas, estando incorporada no sistema jurídico da maioria dos países desenvolvidos como um método regular e habitual de resolução de controvérsias. De tal modo que, para Lacroix (2001, p. 43-44), esse instituto leva à justiça que mais se acerca do ideal, já que surge de um acordo entre as partes, priorizando a autonomia da vontade sobre todos os aspectos do processo.

A arbitragem poderia ser considerada ainda uma justiça que mais se acerca do ideal, não somente porque surge de um acordo de vontades, mas porque promove $\mathrm{o}$ desenvolvimento como liberdade nos seus principais aspectos: incentiva o exercício da condição de agente e prima pelo interesse social. Estes pontos coadunam, portanto, com o ideal de justiça do liberalismo igualitário de John Rawls ${ }^{10}$ (2002) e de Amartya Sen que defende a justiça distributiva como melhor forma de justiça, por estar apoiada na equidade. Justiça, assim, na concepção de Vita (1998, p. 67), "consistiria na eqüidade nos termos que governam um sistema de reciprocidade das dimensões da sociedade. O sistema consiste em cada pessoa dar apoio à estrutura social básica e dela retirar benefícios".

Para Sen (2001, p. 153), existe a realização da justiça na equidade, quando realizada a capacidade social ou de bem-estar social, que corresponde à função da combinação de vetores de funcionamentos de todas as pessoas (ou dos conjuntos capacitários de todos).

Deve-se esclarecer, contudo, que não existe igualdade perfeita. Como específica Cappelletti e Garth (1998, p. 15), "as diferenças entre as partes não podem jamais ser completamente erradicadas. A questão é saber até onde avançar na direção do objetivo utópico e a que custo. Em outras palavras, quantos dos obstáculos ao acesso efetivo à Justiça podem e devem ser atacados?".

Nessa medida, a justiça presente na arbitragem abranger valores sociais e de igualdade, por conceder autonomia às partes, mas também delimitá-la dentro de parâmetros sociais.

Existe, sobretudo, na arbitragem, como ressalta Lima (1994, p. 21), uma tendência “à obtenção de consenso, antes do que uma condenação, evitando o acirramento de ânimos entre pessoas que tenham que persistir convivendo, coexistindo na mesma comunidade, no mesmo meio". A preocupação para que as partes solucionem os conflitos de maneira amigável pode

\footnotetext{
${ }^{10} \mathrm{Na}$ interpretação de Sen (2011, p. 95), "Rawls reconhece indiretamente a importância da liberdade humana em dar às pessoas oportunidades reais - por oposição àquelas apenas formalmente reconhecidas - para fazerem o que bem entendam com suas próprias vidas. [...] E ainda, ao destacar instrumentalmente a importância da liberdade humana, Rawls deu, eu diria, um lugar definitivo para o pensamento relacionado à liberdade dentro do corpo principal da teoria da justiça”.
} 
ser percebida na lei de arbitragem que incentiva, inclusive, a conciliação ou a mediação ao longo de todo o processo.

A opção pela não-litigiosidade também está presente na execução de sentenças arbitrais, tendo em vista que, geralmente, as sentenças arbitrais são cumpridas voluntariamente e sem maiores objeções pela parte devedora, pois as partes prestigiam e recorrem a esse meio de solução de controvérsias com o intento de verem suas pretensões atendidas de maneira rápida e eficaz, até porque estão cientes de que da sentença arbitral não cabe recurso ao Poder Judiciário.

Para Magalhães (1986, p. 102), o fato de a sentença arbitral vir de um julgador (árbitro) escolhido pelas partes faz com que estas reconheçam a decisão como decorrente do exercício da sua própria autonomia. Assim, a sentença arbitral se constituiria um desenvolvimento natural do relacionamento das partes e se funda na confiança que se estabelece com o julgador (árbitro) escolhido consensualmente de maneira que, "se as partes voluntariamente deliberarem submeter uma controvérsia a arbitragem, é porque estão predispostas a aceitar a decisão que vier a ser tomada." (MAGALHÃES; BAPTISTA, 1986, p. 103)

Outro ponto que não vincula os ensinamentos do liberalismo tradicional à arbitragem diz respeito à interferência estatal, pois, segundo Rocha (1998, p. 16-17), "para os liberais a solução está, pois, em eliminar a intervenção do Estado na liberdade dos indivíduos por ser o sistema da livre-iniciativa individual o que permite mobilizar, o melhor possível, as informações, conhecimentos e competências necessários à regulação da vida social". E essa visão individualista e atomista da sociedade presente no liberalismo teria como consequências que: "(1) [... a] "regulação da vida social deve resultar preferencialmente da livre competição entre os indivíduos (mercado) e; (2) a intromissão do Estado só se justifica para garantir a liberdade individual". (ROCHA, 1998, p. 17).

Em outra perspectiva, a intervenção do Estado na arbitragem não visa apenas à garantia da liberdade individual, mas sim à proteção da segurança jurídica e dos valores igualitários que são valores essenciais da teoria de desenvolvimento de Sen (2000). Essa intervenção pode ser encontrada, por exemplo, nas exigências previstas na lei de arbitragem para assegurar a proteção da parte hipossuficiente quando da inserção de cláusula compromissória nos contratos de adesão e nas hipóteses prevista na legislação que autorizam as partes a buscar a nulidade da sentença arbitral quando o processo arbitral violou o princípio do devido processo legal.

A liberdade encontrada na arbitragem não é ilimitada. Como recorda Castro (1999, p. 43), “[...] a vontade das partes tem a liberdade de pássaro na gaiola; pode se mover em certos limites, mas em qualquer direção encontra barreira instransponível". Essas barreiras instransponíveis são utilizadas para dar um perfil mais social à arbitragem, evitando abusos que dela pudessem ocorrer ao sentido de liberdade e de justiça incorporado e aceito pela sociedade.

Dessa maneira, como ressalta Welber Barral (2000, p. 51), a arbitragem não pode ser exorcizada como a "[...] institucionalização da hegemonia do poder econômico", temendo-se "[...] enfim que a arbitragem configure a definitiva privatização da justiça, em prol daqueles que detêm o poder econômico, e em detrimento da cidadania, conquistadas após árduo processo histórico". Assim nem a arbitragem merece zelo apologético, que lhe outorgue o poder mágicos de resolver os problemas do Judiciário nacional, nem constitui ameaça à salvaguarda da cidadania protagonizada pelos juízes. (BARRAL, 2000, p. 51).

Outro ponto importante para a sociabilidade da arbitragem é o seu entrelaçamento como Poder Judiciário, de tal forma que "será no Poder Judiciário que grande parte da lei de 
Arbitragem encontrará a sua interpretação" (SANTOS, 2000, p. 8). Acrescenta ainda que ao Poder Judiciário caberá: apreciar e decidir os pedidos de nulidade da sentença arbitral; proceder aos atos judiciais que darão garantia a efetivação da sentença arbitral; suprir a vontade da parte recalcitrante que celebrou cláusula compromissória incompleta e se recuse a firmar o compromisso arbitral; velar para que a arbitragem não viole os princípios da ordem pública e dos bons costumes. (SANTOS, 2000, p. 8)

Em países em que se tentou desvincular a arbitragem do Poder Judiciário, houve uma experiência catastrófica. Esse foi o caso da Bélgica, por exemplo. Valença Filho (2002, p. 22), retratando tal experiência, expõe que,

Com o fito de promover aquela praça internacional de arbitragem [Bélgica], o legislador proibiu seu juiz estatal de conhecer pedidos de anulação de sentenças arbitrais lá proferidas, sempre que nenhuma das partes fosse pessoa física nacional ou residente naquele país, ou jurídica que lá detivesse a sua sede ou sucursal. Em suma, aboliu-se a possibilidade de ataque às sentenças quando ambas as partes fossem estrangeiras. Os resultados, decepcionantes, demonstram que, se os operadores do comércio internacional querem uma justiça específica, administrada de forma diferente, não a querem, assim, tão distante do Judiciário.

Tem-se, portanto, que a intervenção do Estado na arbitragem não deve ser nem mínima nem máxima, e sim o suficiente para, com isso, permitir que a arbitragem venha a ser reconhecida como um dos instrumentos possíveis para assegurar a realização da liberdade como desenvolvimento, preconizada por Sen (2000).

\section{Considerações finais}

Esse artigo teve como objetivo analisar se a arbitragem pode ser considerada um instrumento de desenvolvimento como liberdade no Brasil. Para tanto, utilizou-se como teoria de base a obra Desenvolvimento como liberdade, de Amartya Sen (2000), que considera o desenvolvimento como a atribuição de capacidade às pessoas para realizarem tudo aquilo que consideram valioso fazer ou ter. Para Sen (2000), o verdadeiro desenvolvimento consiste em eliminar as privações de liberdade que limitam as escolhas e as oportunidades das pessoas de exercer ponderadamente sua condição de agente. A liberdade, dessa maneira, é considerada o meio e o fim do desenvolvimento.

Observou-se que a liberdade proposta não está vinculada as ideias do liberalismo econômico e do individualismo liberal. Entretanto, percebe-se que a teoria de desenvolvimento apresentada por Sen (2000) tem como objetivo dar ênfase ao interesse social e não ao bem-estar individual propriamente dito, o que o conecta com as diretrizes do liberalismo igualitário.

Assim, o crescimento econômico, o mercado, bem como a liberdade individual ampla e ilimitada, são considerados pontos secundários da teoria do desenvolvimento preconizada por Sen (2000) pois, em primeiro lugar, devem estar as condições básicas para que a pessoa tenha uma vida digna e que deve ser alcançada por meio da eliminação das privações de liberdade e pelo exercício da condição de agente. Tal ponto leva a considerar que a liberdade presente na arbitragem, por meio da autonomia privada, possui as características da liberdade vislumbrada por Sen (2000), pois se traduz num direito de escolha do meio de administração de conflitos que é fruto da autonomia das partes, mas fiscalizado pelo Estado. 
Entretanto, os limites impostos à arbitragem e ao seu princípio basilar da autonomia, como a ordem pública, por exemplo, não confronta a teoria de desenvolvimento como liberdade. Isso porque a teoria de desenvolvimento como liberdade percebe a liberdade dentro de um contexto coletivo e não meramente individual. A liberdade deve compreender também os valores sociais e dessa maneira, vai encontrar na igualdade social as suas adaptações.

Assim, a arbitragem, como prevista no sistema jurídico brasileiro - incorporando as ideias de liberdade, de autonomia, de igualdade, de intervenção necessária do Estado e condizente com a teoria de justiça igualitária -, preenche sob medida as especificidades da teoria de Sen (2000) e, portanto, deve ser considerada como instrumento viável de desenvolvimento como liberdade, incentivando a condição de agente mediante a capacidade individual e social e eliminando as privações de liberdade impostas às partes carentes de uma devida tutela jurisdicional.

\section{Referências}

BARRAL, Welber. A arbitragem e seus mitos.Florianópolis: OAB/SC, 2000.

BOBBIO, Norberto. Igualdade e liberdade. Tradução de Carlos Nelson Coutinho. Rio de Janeiro: Ediouro, 1996.

BRAGA NETO, Adolfo. Os advogados, os conflitos e a mediação. Disponível em: www.imab.org.br. Acesso em 8 ago. 2021.

BRASIL. Lei no 9307 de 23 de setembro de 1996. Disponível em:

http://www.planalto.gov.br/ccivil_03/leis/19307.htm. Acesso em 11 set. 2021.

BRASIL. Lei $\mathbf{n}^{\mathbf{0}} \mathbf{1 3 1 2 9}$ de 24 de maio de 2015. Disponível em

http://www.planalto.gov.br/ccivil_03/_Ato2015-2018/2015/Lei/L13129.htm\#art1. Acesso em 11 set. 2021.

BRASIL. Lei $\mathbf{n}^{\circ} 13140$ de 26 de junho de 2015. Disponível em: http://www.planalto.gov.br/ccivil_03/_ato2015-2018/2015/lei/113140.htm. Acesso em 12 set. 2021.

CAHALI, Francisco José. Curso de arbitragem. 3. ed. São Paulo: Editora Revista dos Tribunais, 2013.

CAPPELLETTI, Mauro; GARTH, Bryant. Acesso à justiça. Tradução de Ellen Gracie Northfleet. Porto Alegre: Fabris, 1998, p. 15.

CARMONA, Carlos Alberto. Arbitragem e processo. 3. ed. São Paulo: Editora Atlas, 2009.

CARNEIRO, Paulo Cezar Pinheiro. Acesso à justiça: juizados especiais cíveis e ação civil pública. Rio de Janeiro: Forense, 1999.

CASTRO, Amílcar de. Direito internacional privado. Rio de Janeiro: Forense, 1999. 
CHODOSH, Hiram. Judicial mediation and legal culture. In: Issues of democracy: mediation and the courts. Electronic Journals of the U.S. Department of State. V. 4, n. 3, dec. 1999. Disponível em: https://usa.usembassy.de/etexts/gov/ijde1299.pdf. Acesso em: 10 set. 2021.

CONSELHO NACIONAL DE JUSTIÇA. Justiça em números 2020: ano base 2019. Brasília: CNJ, 2020.

DAKOLIAS, Maria. O Setor Judiciário na América Latina e no Caribe: elementos para reforma. Wahington: Banco Mundial, 1996.

FIUZA, Cézar. Teoria geral da arbitragem. Belo Horizonte: Del Rey, 1995.

FIGUEIRA JÚNIOR, Joel Dias. Arbitragem, jurisdição e execução:análise crítica da Lei 9.307, de 23.09.1996. 2. ed. rev. e atual. do Manual da arbitragem. São Paulo: Revista dos Tribunais, 1999.

JEANTET, Thierry. O indivíduo coletivo. Tradução de Laurent L. Schaffter. Sao Paulo: Vértice, 1986.

LACROIX, Carlos A Filártiga. ¿El primer arbitraje? In: PUCCI, Adriana Noemi (Coord.). Aspectos atuais da arbitragem:coletânea de artigos sobre arbitragem. Rio de Janeiro: Forense, 2001.

LEMES, Selma. Arbitragem em números e valores 2020. Disponível em: https://www.migalhas.com.br/arquivos/2021/1/8D798318F697FE_Analise-PesquisaArbitragensNs.pdf. Acesso em 11 set. 2021.

LIMA, Cláudio Vianna de. A arbitragem no tempo: o tempo na arbitragem. In: GARCEZ, José Maria Rossani. A arbitragem na era da globalização. 2. ed. Rio de Janeiro: Forense, 1999.

MAGALHÃES, José Carlos de; BAPTISTA, Luiz Olavo. Arbitragem comercial. Rio de Janeiro: Freitas Bastos, 1986.

MAGRO, Maíra Evo. Arbitragem começa a ser utilizada em contratos de direito imobiliário. Valor Econômico, Legislação e tributos, São Paulo, p. E1, 21 nov. 2002.

MARTINS, Pedro A. Batista. Embaraços na implementação da arbitragem no Brasil, até o advento da Lei n. ${ }^{\circ}$ 9.307/96 e a pseudo-inconstitucionalidade do instituto. In: MARTINS, Pedro A. Batista; LEMES, Selma M. Ferreira; CARMONA, Carlos Alberto. Aspectos fundamentais da lei de arbitragem. Rio de Janeiro: Forense, 1999.

NORONHA, Fernando. O direito dos contratos e seus princípios fundamentais. São Paulo: Saraiva, 1994. 
PINHEIRO, Armando Castelar. Economia e justiça: conceitos e evidência empírica. Julho de 2001, p. 2. Disponível em: www.ifb.com.br/documentos/castelar18_10.pdf. Acesso em: $1^{\circ}$ out. 2004.

. (Org). Judiciário e economia no Brasil [online]. Rio de Janeiro: Centro Edelstein de Pesquisas Sociais, 2009. Disponível em: http://www.precog.com.br/bc-

texto/obras/castelar-9788579820199.pdf. Acesso em: 10 set. 2021.

POSNER, Richard A. Creating a legal framework for economic development. The World Bank Research Observer, v. 13, n. 1, Feb. 1998. Disponível em: https://documents1.worldbank.org/curated/en/362191468148521481/pdf/766150JRN0WBRO 00Box374385B00PUBLIC0.pdf. Acesso em: 10 set. 2021.

PUCCI, Adriana Noemi. Juiz \& árbitro. In: PUCCI, Adriana Noemi (Coord.). Aspectos atuais da arbitragem: coletânea de artigos sobre arbitragem. Rio de Janeiro: Forense, 2001.

RACINE, Jean-Baptiste. L'arbitrage commercial international et l'ordre public. Paris: Librairie Générale de Droit et de Jurisprudence, 1999.

RAWLS, John. Uma teoria da justiça. São Paulo: Martins Fontes, 2002.

RICCI, Edoardo Flavio. Lei de Arbitragem brasileira: oito anos de reflexão: questões polêmicas. São Paulo: Revista dos Tribunais, 2004.

ROCHA, José de Albuquerque. A lei de arbitragem (Lei 9.307, de 23.9.1996): uma avaliação crítica. São Paulo: Malheiros, 1998.

ROSAS, Roberto. Judiciário brasileiro: de 1969 ao final do século XX. In: NEQUETE, Lenine. O Poder Judiciário no Brasil a partir da Independência:II - República. Brasília: Supremo Tribunal Federal, 2000.

SANTOS, Ricardo Soares Stersi dos. Noções gerais da arbitragem. Florianópolis: Fundação Boiteix, 2004.

. Prefácio. In. BARRAL, Welber. A arbitragem e seus mitos. Florianópolis:

OAB/SC Editora, 2000.

SEN, Amartya. Desenvolvimento como liberdade. Tradução de Laura Teixeira Motta. São Paulo: Companhia das Letras, 2000.

SEN, Amartya. Desigualdade reexaminada. Tradução de Ricardo Doninelli Mendes. Rio de Janeiro; São Paulo: Record, 2001.

A ideia de justiça. Tradução de Denise Bottmann e Ricardo Doninelli Mendes. São Paulo: Companhia das Letras, 2011.

SILVA, Adriana dos Santos. Acesso à justiça e arbitragem: um caminho para a crise do Judiciário. Barueri: Manole, 2005. 
STRENGER, Irineu. Da autonomia da vontade: direito interno e internacional. 2. ed. São Paulo: LTr, 2000.

Autonomia da vontade em direito internacional privado. São Paulo: Revista dos Tribunais, 1968.

TEIXEIRA, Sálvio de Figueiredo. A arbitragem no sistema jurídico brasileiro. São Paulo, Revista dos Tribunais, v. 735, 1997, p. 39-48.

VALENÇA FILHO, Clávio de Melo. Poder judiciário e sentença arbitral. Curitiba: Juruá, 2002.

VITA, Álvaro de. Duas interpretações da motivação moral. In: FELIPE, Sônia T. (Org.). Justiça como eqüidade:fundamentação e interlocuções polêmicas (Kant, Rawls, Habermas). Florianópolis: Insular, 1998. 